\title{
Modelling Organizational Violence in the Covid-19 Era
}

\author{
Enrique Martínez-Muñoz*, Arturo Sánchez-Sánchez, Cruz García-Lirios
}

Department of Legal Medicine, Toxicology and Forensic Medicine, Jordan University Of Science \& Technology, Jordan.

*Corresponding Author: Enrique Martínez-Muñoz, Department of Legal Medicine, Toxicology and Forensic Medicine, Jordan University Of Science \& Technology, Jordan.

Received date: September 29, 2021; Accepted date: December 27, 2021; Published date: January 05, 2022

Citation: Enrique Martínez-Muñoz*, Arturo Sánchez-Sánchez, Cruz García-Lirios. (2022). Modelling Organizational Violence in the Covid-19 Era. J. Neuroscience and Neurological Surgery. 11(3); DOI:10.31579/2578-8868/194

Copyrights: () 2022 Enrique Martínez-Muñoz, This is an open-access article distributed under the terms of The Creative Commons Attribution License, which permits unrestricted use, distribution, and reproduction in any medium, provided the original author and source are credited

\begin{abstract}
In the context of organizations and their relationship with the increasingly competitive environment, leaders have been pressured to establish control systems in which the differences between employees are exacerbated since, in the absence of labor competencies, these are They are intended to substitute for acts of loyalty to the company that lead to violence towards those who are the culprits of poor performance or are not seen as part of a working group. This is how organizational violence is justified within collaborative teams, as would be the case of Higher Education Institutions where the phenomenon is exacerbated with the emergence of electronic technologies, devices, and networks. The objective of this study was to establish the reliability and validity of an instrument that measures organizational violence. A non-experimental, cross-sectional, and confirmatory study was carried out with a non- probabilistic selection of 100 students from a public university in central Mexico. The results in general show that organizational violence would be made up of eight factors such as: prejudice, depersonalization, benevolence, harassment, subjugation, objectification, stigma, and harassment, which show the limits of the study and guidelines of research concerning equity.
\end{abstract}

Key words: formation; organizing violence; sexism; benevolence

\section{Introduction}

Until March 2021, the pandemic has claimed the lives of two million in the world (WHO, 2021). In Mexico, about 500 deaths are estimated related to the SARS CoV-2 coronavirus and the Covid-19 disease (PAHO, 2021). In this scenario, mitigation policies focused on confinement and social distancing, affecting remote work. In this sense, Mexican organizations, by registering the lowest salaries among the member countries of the Organization for Economic Cooperation and Development (OECD), reveal a culture and environment conducive to questioning labor rights (OECD, 2021).

Coupled with the economic and occupational situation, the pandemic intensified the differences between employees by confining them to their residences and living with family members in a small and crowded space (Chaparro, 2020: p.113; Islam, Jerin, Hafiz, Nimfa, \& Wahab, 2021). In this way, the study of violence in the Covid-19 era supposes a wide spectrum of differences between the parties involved but also the inhibition of commitment and innovation. On the one hand, the family context is pointed out, and on the other, the development and transition from the work context to the interior of the home; since the literature recognizes that the family is the first support and care network (Angley, Divney, Magriples, \& Keshaw, 2015; Bae, 2015; García, García, \& Rivera, 2016).
Therefore, the objective of the present work was to confirm the structure of labor and domestic violence that is generated in confinement and prolonged social distancing and in confined and crowded spaces.

Based on the questioning are there significant differences between workplace and domestic violence reported in the literature with respect to the factors established in the present study? it is intended to address the phenomenon of study.

The premise that guides this work refers to the fact that domestic or intrafamily violence has spread to the workplace, but with the advent of the pandemic it is possible to observe an inverse process of importation of workplace violence to the residential niche (Casados, 2020: p. 215). Considering that central Mexico is distinguished by its high population density and family overcrowding, this labor violence transferred to the domestic space is distinguished by dimensions related to the differences between the parties in tension, as well as the prolongation of the situation (Herrera et al., 2021: p. 1027). As the confinement intensifies, workplace and domestic violence increases, but merging in dimensions that demonstrate a diversification of the modes and forms of violence. In this way, it is expected that not only will there be significant differences between the theoretical dimensions with respect to the established factors, but it is also assumed that such factors will make it possible to predict or anticipate scenarios of greater conflicts between the parties.

Organizational violence theory 
The present work is part of the discipline of Social Work, an area of institutional studies, but includes concepts related to the psychology of organizations such as entrepreneurship, the sociology of work for the case of human capital and labor economics for the case of knowledge networks (García, 2020).

Therefore, the objective of this work is to establish the reliability and validity of an instrument that measures violence in electronic networks. Violence, for the purposes of this work, consists of the differentiation between two or more actors with respect to a relationship of power and influence that configures a system of personal and organizational insecurity or security (Salamzadeh, Nejati, \& Salamzadeh, 2014).

In this way, violence in digital networks is based on prejudice, depersonalization, benevolence, harassment, subjugation, objectification, stigma and harassment through a technology or devices in information and digital communication protocols (Carreon et al., 2020). Consequently, at the level of organizations, violence in digital networks is part of an asymmetric professional training process in which the differences between leaders and employees overlap towards the climate of relationships between employees, generating a subsystem of violence in that the employees close to the leaders are the beneficiaries of the vicious circle of differentiation. Indeed, technological educational, scientific and seems to obey an organizational logic in which training professional and violence degree of policy Organizational are factors that explain the differences between countries that allocate amounts similar investment and similarities between countries that support their production from different budgetary and financial amounts.

The theoretical frameworks that explain organizational formative violence are: 1) theory of reasoned action, 2) theory of planned behavior, 3) theory of spontaneous processing and 4) theory of knowledge networks.

The argues that attitudes are mediators of the effect of beliefs about the intentions and acts. An increase in beliefs increases dispositions towards specific and deliberate decisions and actions. It is a process that goes from the general, in terms of beliefs, to the in terms of intentions and actions. However, the predictive power of the general belief is to be bounded, by the specificity and dimensionality of attitudes. Given that attitudes convey the effect of beliefs, they delimit their indicators in dispositions likely to be carried out (Castel \& Freundlich, 2010).

The theory of planned behavior warns that the effect of beliefs on behavior is mediated by attitudes and perceptions of control. In a contingent situation or event, the perception of control increases its predictive power of intentions and behaviors if and only if it interacts with specific dispositions. To the extent that the perception of control decreases, its relationship with attitudes makes a minimal effect on decisions predictable. Necessarily, the deliberate and planned process of decision-making and strategy implementation requires a perception of control consisting of the dispositions towards the object (Castro and Martins, 2010). The attitudes because of the activation of experience with the attitude object. Attitudes are associations between evaluations of objects. A negative evaluation increases the disposition and with it the spontaneity of the behavior (Caykoylu et al., 2011).

A network is a set of central and peripheral nodes around which symmetric or asymmetric interaction relationships are established. In the first case, the central nodes are distanced from the peripheral nodes. The informational gap between the nodes is explained by the discontinuous transfer of knowledge. In the second case, the differences between central and peripheral nodes are reduced to a minimum, facilitating the exchange of information (Fuentes \& Sánchez, 2010). The theory of knowledge networks states that universities and companies are nodes of information exchange that become productive relationships through their knowledge exchanges, development of interdisciplinary projects and training flows (Adenike, 2011).

Degree of policy explains collaborative relationships aimed at balancing demands and resources in contexts of scarcity, uncertainty, insecurity and risk. The theory anticipates the emergence of factors such as trust, commitment, and satisfaction that in turn determine innovation and eventually organizational happiness. Professional training networks are information and communication systems related to the development of educational competencies derived from institutional and organizational synergies. They involve information technology systems from which it is possible to build an academic or work identity as long as the nodes form consensus and co-responsibilities around scientific and technological production (Molero, Recio, \& Cuadrado, 2010).

Professional training networks for relations between institutions and organizations are exposed to problems inherent to collaborative relationships (Tajpour, Hosseini, \& Salamzadeh, 2020). In this way, the work environment is the determining factor of agreements, agreements and / or consensuses oriented to organizational development; industrial, scientific, and technological, as well as the innovations of collaborative groups. That is why they are knowledge management instruments and innovations that make it possible to overcome the discrepancy between industrial growth and sustainable development (Coronel, 2010; (Tajpour, Hosseini, \& Salamzadeh, 2020).

The formative violence suggests that the differences between production systems investing similar amounts of money to their processes are organizing climate, asymmetrical relationships violent. In this sense, organizations approach the imbalance between demands and resources, but it is inequity and discretion that allow the adjustment of task relationships to the diffuse objectives of companies (Díaz, 2013). Organizational formative violence, unlike RFP, is indicated by asymmetric and inequitable relationships between the members of the knowledge network. In this way, management is replaced by dogmas; freedoms are displaced by discretion; Opportunities give way to impositions, capacities are reduced to their minimum expression in the face of kinship, and co-responsibilities are inhibited by attributions of guilt (Guillén, Lleó, \& Perles, 2011). Formative violence would be the result of the interrelation between relative and simple majorities and minorities that when innovating increase or decrease their participation in the construction of an organizational climate. This is how professional training networks are power groups that, by centralizing their decisions, generate a formative dissidence and with it the discussion for consensus or the use of violence as a persuasive or dissuasive instrument for knowledge management and technological innovation (Carreón, 2011).

Violence of degree of policy warns of the emergence of an organizational climate that is embodied in discourses of power in which differences, conflicts and disagreements are symptoms of a discretionary management or indicate a consensual management, but on the influence of the majority on minorities. He anticipates the emergence of conflicts that, in his opinion, would explain the increase in creativity more than trust, initiatives and personal efforts more than trust and group commitment, as well as pragmatism more than satisfaction aimed at innovation, but also towards conformity (Tayo and Adeyemi, 2012).

\section{Organizational violence studies}

Organizational violence studies have focused on the deliberate, planned, systematic and improvised process of professional training focused on formative violence such as mobbing, bulling, stalking, and trolling in electronic networks in which that employees of an organization interact (Carreon et al., 2020).

Organizational studies show that the work environment is a preponderant factor in explaining collaborative relationships between employees and managers. In this sense, workplace violence has been identified as a factor adjacent to vocational training since it involves interpersonal and task conflicts that inhibit productivity and competitiveness. Within the framework of the relationship climate and workplace violence, this study is inserted into the discussion about sexism as an inhibitory factor in productive relationships (Borjas, 2010). Despite educational institutions and for-profit organizations pursuing common objectives, the discrepancy 
between responsible professional training and productivity unrelated to sustainability is predominant in the disagreements and conflicts between academic and business actors (Vargas, 2011; Tajpour, Moradi, \& Jalali, 2018).

However, business financing that promotes the specialization of knowledge and technological innovation encourages scientific production towards the optimization of natural resources and thereby disseminates a labor identity contrary to the values of equity, altruism or biosphericism. These are asymmetric relationships in which verticalism, sexism or ostracism are indicators of a field of organizational power from which the management, production, quality, and innovation of knowledge are controlled (Cuesta, 2012). In the educational organizational field, professional training is the process around which it is expected to develop the competencies that will allow the student to enter the workplace. In this sense, the collaboration agreements between universities and companies are aimed at adjusting the skills and knowledge of students to the requirements of the local and global market. This assumes symmetrical relationships between the participants since trust, cooperation, commitment, satisfaction, and ease are indicators of an entrepreneurial training (Gargallo, 2010; Tajpour, Moradi, \& Jalali, 2018).

In contrast, when asymmetric relationships prevail over the members of a network, distrust, selfishness, dissatisfaction and stress emerge as a limiting paradigm of task and collaborative relationships. The analysis of the meanings around the knowledge network by teachers shows a work environment of asymmetric relationships. Around which the absence of professional entrepreneurship is a factor to consider when evaluating the effectiveness of the professional internship program (Gil, 2010). The theoretical frameworks that explain the behavior of knowledge networks through information and communication technologies have established as determining factors the evaluative principles, the beliefs about information and the normative principles of the socialization of the Internet and electronic devices. The relationship between these variables with respect to technological behavior has been established from the assumption according to which attitudes, perceptions and intentions are mediators of the impact of values, beliefs and norms on the use of a technological device (Long, 2010). Innovation is an effect of the exchange of information between research and technology projects and the strategic planning of knowledge. In this sense, a knowledge network implies the collaborative participation of specialists and technologists around a productive-technological activity. Therefore, the configuration of a network is carried out from the organizational-collaborative structure between universities and industrial sectors (Borjas, 2010).

In terms of organizational networks, two types of knowledge converge: codified and tacit. The first refers to productive relationships in which communication of procedures, recruitment and training are responsible for implementing the mission and vision of the organization among human resources (Cerrón, 2010; Tajpour, Moradi, \& Jalali, 2018). The second type of knowledge is articulated from the exchange of procedures not written in a manual but transferred by the more experienced staff to the new staff. These are beliefs and values around the execution of tasks, the use of technical equipment and production-distribution procedures (Coronel, 2010). Both types of knowledge symbolize the construction of an organizational-labor-technical culture around which trust is fundamental. E 1 trust factor absent involves setting up a network could not be carried out since collaborative learning requires a distribution of responsibilities where who does not follow the labor dynamics organizational Lima, it is excluded (Cuesta, 2012).

In this sense, knowledge networks require three conditions to survive: horizontal power, redistributed among the members of the network, and the burden of responsibility, aimed at each one of the members of the network. The solution to problems after the network configuration is in the network itself. Therefore, decisions are established through an induction mechanism rather than a selection mechanism (Díaz, 2013). An essential factor of the network is the translators who have skills and knowledge about the needs of operational staff and the requirements of administrative staff around strategic planning of goals. If different languages are considered between the growth needs of a company and basic research, translators are essential since their transdisciplinary training and their theoretical-applied experience are a link between entrepreneurs, administrators, and staff (Gil, 2010).

Self- efficacy is a perception and / or a belief motivated by trials of personal or impersonal successes and errors carried out deliberately or discursively. Given that self-efficacy refers to failure, but mainly to success, even despite those failed trials that encourage achievement, the perception and belief of self-efficacy is based on the achievement of expected objectives rather than on competitiveness, recognition or learning vicar. If self-efficacy is a system of perceptions and beliefs focused on success, then the group to which the self-effective agent belongs or wants to belong is related to success. Because groups are diverse, self-efficacy varies based on this diversity. A competitive group attributes success to one of its members when he has exceeded previous achievements, which by the way were set by the group. In this sense, the concept of self-efficacy seems reliably adjusted to the influence of a group on the objectives, system, and achievements of an individual (Anwar \& Norulkamar, 2012). If self-efficacy is a system of perceptions that encourage achievement by delimiting effective capacities, self-efficacy would also be a system of perceptions and beliefs, but unlike self-efficacy, these would be oriented to the execution of a procedure or technology. The factors that drive self-efficacy would be identical in the case of self-efficacy. If competitiveness, recognition, and vicarious learning drive self-efficacy, then self-efficacy would also have that drive (Arnau \& Montané, 2010; Farzad, Salamzadeh, Amran, \& Hafezalkotob, 2020).

Attitudinal psychological studies have focused on its conceptualization, formation, activation, accessibility, structure, function, prediction, change, inoculation, identity, and ambivalence. Attitudes have been defined based on emotional and rational dimensions. Both dimensions are the result of experiences and expectations. This implies its structure: unidimensional or multidimensional that is configured in exogenous and endogenous factors. That is, when attitudes activate decisions and behaviors, they cause a peripheral, emotional, spontaneous, heuristic, and ambivalent process. In contrast, when attitudes transmit the effects of values and beliefs on intentions and actions, they are endogenous mediators of a central, rational, deliberate, planned, and systematic process (Berdecia, González \& Carrasquillo, 2012; Tajpour, Moradi, \& Jalali, 2018).

Psychological studies have shown significant differences between attitudes towards people and attitudes towards objects. The former refers to stereotypes or attributes and the latter refer to evaluations or dispositions. In both, ambivalence is an indicator of change when beliefs and evaluations interact, forming negative and positive dispositions towards the object. Conflicts are formed within the components formed by beliefs towards the object. Resistance to persuasion is a consequence of attitudinal ambivalence. If the environment threatens the formation and function of attitudes, These, will adapt the individual to contingencies. In this way, attitudes have two essential functions: selfish and utilitarian (Cardon et al., 2013).

Attitudinal change refers to emotions and affections that are consequential to individual acts and for which people feel responsible. It is also about the social influence that the teaching groups exerted on the students. Or, the reception of persuasive messages aimed at central reasoning, or persuasive messages aimed at peripheral emotionality. In general, the attitudinal system is sensitive to the instability of the object and to cognitive variations that affect the consistency, stability, prediction, competence, or morality of the individual (Celik, Turunc \& Begenirbas, 2011). Consistent changing attitudes is to relate to its multidimensional structure resulting from the majority pressure. The 
diversity of dimensions implies a consistent construction of attitudinal change. That is, attitudes assume a function of internalized responses to constant situations framed by the mass media (Chiang, Méndez \& Sánchez, 2010). Attitudinal change is to relate to the deterrent principle of inoculation. Before the attack of persuasive messages, the perception of threats, risk and uncertainty is induced. In general, overexposure to present messages induces a high development and thereby persuasion. The massive delivery of persuasive messages, motivation, and consequent management skills can lead to helplessness. That is, before the wave of information, people reduce their perception of control and tend to believe that events are immeasurable, unpredictable, and uncontrollable. Or individuals form an identity that consists of identifying with an administrative group about a teaching group. In the process of helplessness, the individual builds the change of attitude and its reinforcement of hopelessness. In the identity process, it is the group that influences the person's attitudinal change. Helplessness is a process of self-validation or prophecy self-fulfilled. In contrast, identity is a convergent validation of group norms (Chinchilla \& Cruz, 2010).

The social influence of the teaching group or administrative group refers to the majority norms and minority principles oriented to attitudinal change. The influence of majorities fosters individual conformity and minority principles, conflict, and attitudinal change. Recently, the minority style has turned out to be the most permanent factor of social influence and attitudinal change. In other words, the construction of majority consensus seems to have an ephemeral effect and the construction of dissent seems to offer constant change (Díaz, Hernández, \& Roldán, 2012).

Studies of attitudes toward behavior have focused on their ambivalence. as people try to balance the favorable and unfavorable information to the dispositional order keeping ambivalent attitudes. That is, attitudinal objects are part of the environment in which people find themselves and their need to order, predict and control it. Therefore, although the attitudinal object is consistent with their perceptions, values and beliefs, people must contrast these objects with the behaviors associated with them (Figeiredo et al., 2012).

Education is a system of knowledge networks that make up a teachinglearning cycle. At the beginning of the educational cycle, knowledge networks are just a blueprint (Kawamorita, Salamzadeh, Demiryurek, \& Ghajarzadeh, 2020). Production strategies are guided by an emerging paradigm rather than dominant. It is about the plausibility of theories because knowledge is hardly supported by ideologies. The second stage of the educational cycle is peer evaluation, which consists of adjusting the projects to the policy of the administrative group. Subsequently, in the third stage, the diffusion of knowledge is observed in institutional academic spaces (Fuentes, Herrero, \& Gracia, 2010).

Studies on knowledge networks warn that the formation of groups and project planning are as important as trust and identity around an organization, institution, or university. The formation of groups has its origin in the social psychological processes of categorization, comparison, representation, and social identity around which conflict and change are the foundations of knowledge networks (Galindo, \& Echavarría, 2011).

Conflict precedes change. These are asymmetric relationships between the members of a group about members of another group considered as alien to the common interests of a group. Conflict emerges when differences between groups are evident. The conflict emerges now in which one of the students violates the practice regulations affecting knowledge transfers. Since the teacher-researchers are responsible for managing and training students in their insertion into the mission and vision of the organizations, they must ensure compliance with the regulations and sanction those who violate the collaboration rules (Holden \& Karsh, 2010; Farzad, Salamzadeh, Amran, \& Hafezalkotob, 2020).
Another type of conflict, the one related to innovation defined as the influence of a persevering minority in their actions with the intention of persuading or dissuading an administrative group. It lies within the organization or the university, it is the conflict in which the students involved perceive a greater use of their capacities and resources. Consequently, they demand greater management and training to achieve objectives focused on administrative-technological innovation (López \& López, 2011).

On the other hand, change is a consequence of conflict. It is a process in which conversion precedes persuasion that triggered a conflict and a central or peripheral attitude of need for cognition. The attitudinal change around the questioning of convictions alludes to a dissuasive process in which the information can be rationalized or emotional. In the first case, the need for cognition can lead to a dissonance in which the information does not match expectations. In the second case, the information fosters emotions that increase expectations towards the informational-attitudinal object (Morales, Ariza, \& Muñiz, 2012). In this sense, change is also synonymous with conversion in which attitudes towards an object lead to a modification of the individual's behavior towards the group (Ríos, Téllez \& Ferrer, 2010). In the case of knowledge networks, conflict and change are essential processes to understand the barriers and the facilities of knowledge transfer between symmetric and asymmetric groups around the information of an object, process, institution, or organization (Rodríguez, Retamal, Lizana, \& Cornejo, 2011).

Individuals establish categories, comparisons, identities, and representations around themselves in relation to members of a group and about other individuals belonging to other groups (Rojas, García, \& García, 2011). By establishing benchmarks, conflicts within an academic group can be transferred to conflicts between organizational groups. This is the first step for the delimitation of identity or belonging to a group (Shrrof, Denenn, \& Ng, 2011).

The intra and inter-group categorization consists of a set of perceptions around the resources, skills, and capacities within a group about another group. If perception is the biased ordering of objects, groups, and their individuals, they bias their appraisals when evaluating their actions and those of others. This is the case of the attribution bias around which individual perceptions attribute achievements to their abilities and attribute their failures to the abilities of others (Sobrados \& Fernández, 2010).

After categorization and comparison, identity underlies. These are membership decisions based on biased attributive judgments. If a student perceives greater possibilities for personal growth in a group to which he does not belong, he will decide to change or convert his ideas to those of the favored group. In this sense, the knowledge network would be the one most favored by individual judgments and attributions. At this point in the group formation process, two types of reference are constructed: teaching group and administrative group (Theh et al., 2010). The administrative group builds its identity underlying the capacities of the teaching group. In other words, the constitution of a knowledge network is not only carried out from the perceptions of capacity of the members of a group, but also from the incapacity perceptions of the teaching group (Vargas \& Arenas, 2012).

To the extent that an administrative group biases its evaluative judgments, it transfers the teaching group to its conflicts. Perceptual bias turns into attributive bias and ends up as selective bias. By focusing the bias on the teaching group, the individual from the administrative group builds a framework of representations around which the capacities, resources and limits of the administrative group are interpreted about the teaching group (Yáñez, Arenas \& Ripoll, 2010).

The representation of the teaching group competencies supposes an evaluation of their behaviors by the individual and their teaching group. It is a set of emotions and cognitions around the causes of the act of the teaching group in comparison to the actions of the administrative group. That is, individuals only want to observe the acts that contradict 
the administrative group and try to minimize their effects on people's decisions (Zampetakis \& Moustakis, 2013).

To the extent that the individual has contact with the teaching group, he increases his emotions and cognitions around the actions of the teaching group. Precisely, from these experiences it is possible to infer attitudinal processes that explain the exclusion of the teaching group because they are attributed different resources and capacities compared to the administrative group (Yuangion, 2011).

In this process of exclusion, the emotional-cognitive-behavioral consistency that explains the differences between the groups underlies. If the administrative group excludes the members of the teaching group, then it will have shown a high consistency that threatens the consistency of the administrative group. Therefore, individuals who belong to an administrative group tend to see significant differences with respect to the teaching group and its members. The consistency of the administrative group is biased when compared to the teaching group since a biased idea can only be a prejudice rather than an argument (Prada, 2013). In the field of knowledge networks, the consistency of the administrative group and the teaching group is incompatible. For a knowledge network to work, it requires a group administration that can link their knowledge with a group teaching inconsistent in their emotions, cognitions and actions, reasons, knowledge transfer of the administrative group justify synergy groups because it remedies the inconsistency of the group or teacher. This process can also be observed if the administrative group is inconsistent, and the teaching group is consistent (Orantes, 2011).

However, individuals who perceive emotional-cognitive-behavioral inconsistency around the production of knowledge in their administrative group, end up migrating to the teaching group since it will allow them greater personal growth. This migration process is of an emotional-cognitive order since the emotions around the teaching group produce aversion to the administrative group, affinity, and adherence to the teaching group (Omar, 2010).

Translators, those with knowledge, skills, and abilities to manage synergies between the group teaching, they tend to seek data to support their efforts knowledge. However, inaccessibility to the teaching group prevents knowledge management, the formation of synergies and the transfer of knowledge. If individuals have restricted access to a teaching group, they can mimic it with the administrative group and fall under the assumption of natural compatibility of knowledge of both the teaching group and the administrative group. The consequence of this compatibility will be the inhibition of the knowledge network and its turning into corruption, simulation or nepotism around the production and transfer of knowledge. In other words, an increase in inaccessibility to the teaching group increases the chances of failure of organizational, scientific, and technological programs between the administrative group and the teaching group (Medina, 2010). Translators, as knowledge managers, are mediators of relationships between teachers and students. When the organizational climate between the administrative group and the teaching group becomes one of ambiguity and adversity rather than transparency and loyalty, those involved in knowledge networks manipulate information to pursue their interests, translators must persuade both groups of the unsustainability of their relationship. It is not enough to diagnose group differences, it is also essential to reduce risks and uncertainty by enhancing the benefits of each link and node of the knowledge network (Manning, 2010; Kawamorita, Salamzadeh, Demiryurek, \& Ghajarzadeh, 2020).

Now, the affective-behavioral consistency between both groups implies creativity, which introduces an innovative dynamic to both groups. It is a flexible organizational climate in which $\mathrm{s}$ and potentiate ideas about production and transfer of knowledge. Since knowledge networks are diverse, in each link or node it is necessary to heterogenized the production and transfer of knowledge. To the extent that the organizational climate is soft, it increases trust and identity within both groups (Long, 2013).

Trust and identity are the result of a type of persuasive information known as belief and the organizational environment in which beliefs are disseminated is known as attitude towards the knowledge network, its members, and processes. An increase in information related to the network increases the certainty, production, and transfer of knowledge. In contrast, the decrease in information inhibits the group relationship. Consequently, collaborative, and innovative relationships have an impact on productivity, however, stress such as exhaustion, depersonalization or frustration can emerge because of the increase in productive demands (Gil, 2010).

However, a part of the professional training process is only explained since in the organizations there are barriers that inhibit development. In this sense, ambivalence and organizational violence are external to professional training. Therefore, knowledge management involves training networks that innovate in adverse and contingent situations, but also underlie the conflicts and asymmetries inherent to the organizational climate.

In this way, professional training is indicated by conflicts derived from its degrees of organizational discretion. As it intensifies, inequality materializes in monopolistic habits, but a reduction to its minimum expression generates consensus in top management. $\mathrm{L}$ at discretion is discursive or heritage of senior management, persuasion deterrence are products of monopoly or consensual fields. In other words, discretion as an antecedent of monopoly habitus anticipates formative violence since it suppresses innovation and generates conformity and obedience, verticalism, sexism, and ostracism (Carreón, 2013).

However, more recent research has shown that the socialization of information in knowledge networks disseminates its effect on perceptions of utility and risk, as well as on attitudes related to anxiety and addiction to networks, the main determinants of behavior. In this way, technological behavior is determined by information processing around a knowledge network. This effect, being mediated by collaborative decisions, increases the predictive power of beliefs about task and interpersonal relationships in an organization (Adenike, 2011).

On the other hand, collaborative intentions suppose attitudes of trust, perceived capacities, and informative beliefs that, when interrelated, determine the favorable or unfavorable decision-making for a group of knowledge. However, the knowledge construction process would not be feasible without the formation of trust attitudes in which collaborative groups disseminate information that will be categorized into learning or motivation tools aimed at achieving objectives and goals (Cerrón, 2010).

In parallel, the perceived capacities complement the formation of categories of information since it is about skill and knowledge around the construction of a professional training network. However, some studies suggest that professional training and the construction of a network are different processes since they assume selfish values that contradict altruistic values. It is a series of group norms around which individuals are professionally trained or are emotionally oriented when forging an identity. However, it is the socialization of information that will determine the behavior of an individual in a collaborative group (Gargallo, 2010; Salamzadeh \& Dana, 2020).

By way of review, the state of knowledge has explained the organizational performance of groups and collaborative networks in situations of scarcity, uncertainty, insecurity, and risk. Individuals and groups develop a climate of trust potentiate their work commitment and approach to life satisfaction, but also implement a management creative and innovative processes as a response to the contingency. Model put forward by the state of knowledge at the assume that the socialization of knowledge consists of beliefs general information, is general effects on each of the mediating factors of its relationship with the behavior. Therefore, the specification of the dimensions of behavior could indicate that there are other intermediate factors with respect to socialization. These are eight indicators of technological behavior 
which explain the formation of a collaborative group based on information processing.

In the case of trust, technological behavior is indicated by collaborative relationships in which the benefits would not be based on costs, but rather derived from interdependence when carrying out a specific task. In other words, professional training that involves the intensive use of technologies comes from symmetrical relationships that a group establishes to distribute skills and disseminate knowledge. These are committed relationships since if a member does not develop work skills, then they will be excluded from a group that has established a culture of high productive quality. In this sense, collaboration is the result of shared goals, while individualism would be an effect of the goal system that rewards personal effort (Manning, 2010).

In the case of cooperation, unlike simple normative collaboration, technological behavior implies specialized skills and knowledge for the fulfillment of purposes. That is why groups are driven to establish cooperative relationships since the group itself must exchange information, process strategies, or implement techniques that involve continuous support among its members (Medina, 2010; Salamzadeh \& Dana, 2020).

However, another indicator of technological behavior is the empathy among its members since intensive work and the achievement of objectives or the fulfillment of goals implies affective and emotional relationships to reduce personal conflicts to the absence of communication (Omar, 2010). Regarding solidarity, unlike collaboration or cooperation, it involves professional training based on the dynamics of collaborative teams within the knowledge network. While collaboration and cooperation are determined by social values, solidarity goes beyond the normative or evaluative principles that unite the groups, it is an awareness of scarcity and uncertainty that allows anticipating situations of shortage by sharing resources (Orantes, 2011).

Consequently, propensity for the future is the result of solidarity behaviors that anticipate risk scenarios. In effect, collaborative groups are motivated by prevention and coping strategies in situations that are unfavorable to the groups with whom they share objectives and goals (Prada, 2013).

The indicator par excellence of technological behavior is entrepreneurship or dissident spirit. Indeed, the use of a technology and even more so the formation of collaborative networks would not make sense if profits were only pursued in the short or medium term. Vocational training consists of anticipating scenarios of scarcity, risk and uncertainty for which knowledge groups form networks that are essentially entrepreneurs, dissenters from the situations that are coming or the catastrophes that are expected (Vargas, 2011).
Social violence was indicated by hostile sexism in which male gender identity inhibited the development of female gender identity. Gender identity seems to be a condition on which benevolent discourses are developed that confine the function of female identity to the care and attention of the work group or work team. The specification of relationships suggests that organizational formative violence is indicated by eight Factors related to prejudice, depersonalization, benevolence, harassment, subjugation, objectification, stigma, and harassment that make up a climate of relationships and tasks in which discourses emerge that reduce the merits of individuals and enhance the differences between groups (Carreón, 2014; Kawamorita et al., 2020).

The theoretical and empirical relationships selected from the literature on formative violence in electronic networks will be adjusted to the empirical observations carried out in an institutional, organizational, and academic context of central Mexico. The theories and findings reviewed in the literature when explaining the phenomenon of formative violence in different contexts, areas and scenarios will give an account of the institutional and academic situation that prevails in the public university with respect to violence practiced in electronic networks and will even anticipate scenarios of conflict between the actors. Even though the theoretical and empirical frameworks have accounted for the dependency relationships between the factors that explain organizational violence, the specificity of the interrelationships in digital networks, as well as the context of study, exceed the theoretical and empirical assumptions.

\section{Method}

Design. A confirmatory, cross - sectional study of qualitative court held and quantitative.

Sample. A non-probabilistic selection was made of 100 students from a public university. The selection criterion was to belong to the system of practices and social service in organizations and institutions with and without profit aims of the municipality of Chimalhuacán, State of Mexico. Instrument. The Carreon Organizational Formative Violence Scale (2014) was used, which includes 32 statements regarding prejudice, depersonalization, benevolence, harassment, subjugation, objectification, stigma and harassment with five response options ranging from "it does not resemble me situation" to "looks a lot like my situation" (see table 1).

\begin{tabular}{|c|c|c|c|}
\hline Factor & Definition & Reagents & Choices \\
\hline Bullying & $\begin{array}{c}\text { Degree of persecution of individuals } \\
\text { or groups who are blamed for the } \\
\text { results of the organization. }\end{array}$ & 29 to 32 & $\begin{array}{c}0=\text { does not resemble my situation, } 1=\text { very } \\
\text { little resembles my situation, } 2=\text { little } \\
\text { resembles my situation, } 3=\text { somewhat } \\
\text { resembles my situation, } 4=\text { very much } \\
\text { resembles my situation }\end{array}$ \\
\hline Benevolence & $\begin{array}{c}\text { Degree of confinement of individuals } \\
\text { or groups perceived as vulnerable, } \\
\text { marginalized or excluded in the work } \\
\text { environment. }\end{array}$ & 9 to 12 & $\begin{array}{c}0=\text { does not resemble my situation, } 1=\text { very } \\
\text { little resembles my situation, } 2=\text { little } \\
\text { resembles my situation, } 3=\text { somewhat } \\
\text { resembles my situation, } 4=\text { very much } \\
\text { resembles my situation }\end{array}$ \\
\hline Reification & $\begin{array}{c}\text { Degree of minimization of the } \\
\text { achievements of individuals or } \\
\text { groups that collaborate in the same } \\
\text { work process. }\end{array}$ & 21 to 24 & $\begin{array}{c}0=\text { does not resemble my situation, } 1=\text { very } \\
\text { little resembles my situation, } 2=\text { little } \\
\text { resembles my situation, } 3=\text { somewhat } \\
\text { resembles my situation, } 4=\text { very much } \\
\text { resembles my situation }\end{array}$ \\
\hline
\end{tabular}




\begin{tabular}{|c|c|c|c|}
\hline Depersonalization & $\begin{array}{l}\text { Degree of indifference towards } \\
\text { individuals or groups that participate } \\
\text { in the same collaborative process. }\end{array}$ & 5 to 8 & $\begin{array}{c}0=\text { does not resemble my situation, } 1=\text { very } \\
\text { little resembles my situation, } 2=\text { little } \\
\text { resembles my situation, } 3=\text { somewhat } \\
\text { resembles my situation, } 4=\text { very much } \\
\text { resembles my situation }\end{array}$ \\
\hline Stigma & $\begin{array}{l}\text { Degree of attribution of causality to } \\
\text { individuals or groups to which } \\
\text { negative or unfavorable elements are } \\
\text { associated with the organization. }\end{array}$ & 35 to 28 & $\begin{array}{c}0=\text { does not resemble my situation, } 1=\text { very } \\
\text { little resembles my situation, } 2=\text { little } \\
\text { resembles my situation, } 3=\text { somewhat } \\
\text { resembles my situation, } 4=\text { very much } \\
\text { resembles my situation }\end{array}$ \\
\hline Harassment & $\begin{array}{c}\text { Degree of speeches and actions } \\
\text { directed at individuals or groups that } \\
\text { participate in the same collaborative } \\
\text { level. }\end{array}$ & 13 to 16 & $\begin{array}{c}0=\text { does not resemble my situation, } 1=\text { very } \\
\text { little resembles my situation, } 2=\text { little } \\
\text { resembles my situation, } 3=\text { somewhat } \\
\text { resembles my situation, } 4=\text { very much } \\
\text { resembles my situation }\end{array}$ \\
\hline Prejudice & $\begin{array}{l}\text { Degree of attributions of guilt } \\
\text { towards individuals or groups } \\
\text { oriented by trust and commitment } \\
\text { directed towards satisfaction, } \\
\text { innovation, and happiness. }\end{array}$ & 1 to 4 & $\begin{array}{c}0=\text { does not resemble my situation, } 1=\text { very } \\
\text { little resembles my situation, } 2=\text { little } \\
\text { resembles my situation, } 3=\text { somewhat } \\
\text { resembles my situation, } 4=\text { very much } \\
\text { resembles my situation }\end{array}$ \\
\hline Subjugation & $\begin{array}{l}\text { Degree of ignorance of the merits of } \\
\text { an individual or group that } \\
\text { participates in the same collaborative } \\
\text { project. }\end{array}$ & 17 to 20 & $\begin{array}{c}0=\text { does not resemble my situation, } 1=\text { very } \\
\text { little resembles my situation, } 2=\text { little } \\
\text { resembles my situation, } 3=\text { somewhat } \\
\text { resembles my situation, } 4=\text { very much } \\
\text { resembles my situation }\end{array}$ \\
\hline
\end{tabular}

Source: self-made

Table 1: Operationalization of variables

Procedure. The participants were interviewed and surveyed in the university facilities. They were informed that the results of the investigation would neither positively nor negatively affect their school situation. They were asked to answer the questions and statements honestly. They were invited to consult the results in the final report of the research group. The data were processed in the Statistical Package for Social Sciences (SPSS) and the Structural Moment Analysis Software (AMOS) in versions 10 and 6.0.

The parameters of kurtosis, Cronbach's alpha, KMO coefficients, Bartlett's test, factorial weights, Pearson correlations, "phi" covariances, "beta" and "range" weights, as well as adjustment indices and residuals were used to contrast the model of specified relationships with the observed data.

Normal. The kurtosis value close to the unit was assumed as evidence of the normal distribution of the responses of respondents with respect to the statements that measure the study variables in an instrument with response options and interval measurement levels.

Validity. KMO coefficients greater than 0.600 and the Bartlett test with significance level less than 0.050 were assumed as evidence of productmoment correlations that facilitated the exploratory factor analysis of principal components with varimax rotation. Subsequently, factorial weights greater than 0.300 were considered as evidence of the maximization of variance in terms of the factors derived from the exploratory analysis. Percentages of explained variance greater than 0.20 were assumed as evidence of acceptance of the null hypothesis.

Reliability. Cronbach's alpha value greater than 0.70 was assumed to be enough to demonstrate the internal consistency of the indicators with respect to the general scale and the subscales. The product moment correlation higher than 0.90 was considered as evidence of collinearity and multicollinearity, which means that the items are similar in terms of their contents.
Correlation. Pearson's r values close to unity and zero were discarded from subsequent analyzes as they signify collinear or spurious relationships. On the other hand, those values higher than 0.30 and lower than 0.90 were assumed as evidence of dependency relationships.

Covariance. The "phi" values between 0.30 and 0.90 were identified as evidence of dependency relationships for the case of categorical variables or in combination with continuous variables.

Structure. The "beta" values between exogenous and endogenous variables between 0.30 and 0.90 were assumed as evidence of dependency relationships. Similarly, "gamma" values between endogenous variables close to zero or to unity were discarded from subsequent analyzes.

Adjustment. The Goodness of Fit Index (GFI for its acronym in English) close to unity was assumed as evidence of fit and acceptance of the null hypothesis. On the contrary, values lower than 0.975 were considered as evidence of rejection of the null hypothesis and acceptance of the alternative hypothesis.

Residual. Values close to zero were assumed as evidence of fit between the specified relationships and the data obtained, therefore, the null hypothesis of fit between both models was accepted. In contrast, values greater than 0.007 were considered as evidence of rejection of the null hypothesis.

\section{Results}

The Table 2 shows values near zero kurtosis were interpreted as prerequisites for multivariate analysis. In other words, the instrument in general terms seems to be distributed in moments that can be correlated with each other and for this reason, validity and reliability estimates are recommended. 


\begin{tabular}{|c|c|c|c|c|c|c|c|c|c|c|c|c|c|}
\hline$R$ & Regent & $M$ & SD & $\mathrm{K}$ & $\mathrm{A}$ & $F 1$ & $F 2$ & $F 3$ & F4 & $F 5$ & F6 & $F 7$ & $F 8$ \\
\hline 1 & $\begin{array}{lr}\text { My } & \text { superior } \\
\text { recognizes } & \text { my } \\
\text { personal merits } & \\
\end{array}$ & 3.05 & 0.28 & 1.42 & 0.721 & 0.391 & & & & & & & \\
\hline 2 & $\begin{array}{l}\text { My superior ignores } \\
\text { my physical attributes }\end{array}$ & 3.46 & 0.30 & 1.04 & 0.725 & 0.403 & & & & & & & \\
\hline 3 & $\begin{array}{l}\text { My superior ignores } \\
\text { my collaboration }\end{array}$ & 3.08 & 0.56 & 1.26 & 0.749 & 0.506 & & & & & & & \\
\hline 4 & $\begin{array}{l}\text { My superior } \\
\text { recognizes my ability }\end{array}$ & 3.04 & 0.18 & 1.47 & 0.793 & 0.624 & & & & & & & \\
\hline \multirow[t]{3}{*}{5} & $\begin{array}{l}\text { The opposite sex } \\
\text { admires my }\end{array}$ & 2.94 & 0.25 & 1.36 & 0.703 & & 0.405 & & & & & & \\
\hline & & & & & & & & & & & & & \\
\hline & physical attributes & & & & & & & & & & & & \\
\hline 6 & $\begin{array}{l}\text { The opposite sex } \\
\text { acknowledges my self- } \\
\text { denial }\end{array}$ & 2.48 & 0.39 & 1.39 & 0.794 & & 0.571 & & & & & & \\
\hline 7 & $\begin{array}{ll}\text { The opposite } & \text { sex } \\
\text { ignores } & \text { my } \\
\text { collaboration } & \\
\end{array}$ & 2.04 & 0.47 & 1.63 & 0.791 & & 0.682 & & & & & & \\
\hline 8 & $\begin{array}{l}\text { The opposite sex } \\
\text { admires } \\
\begin{array}{l}\text { contribution to the } \\
\text { team }\end{array}\end{array}$ & 2.39 & 0.18 & 1.82 & 0.739 & & 0.732 & & & & & & \\
\hline 9 & $\begin{array}{l}\text { My superior exalts } \\
\text { my physical beauty }\end{array}$ & 3.01 & 0.26 & 1.05 & 0.729 & & & 0.516 & & & & & \\
\hline 10 & $\begin{array}{l}\text { My superior ridicules } \\
\text { my physical attributes }\end{array}$ & 3.82 & 0.04 & 1.27 & 0.740 & & & 0.663 & & & & & \\
\hline 11 & $\begin{array}{lr}\text { My } & \text { superior } \\
\text { emphasizes } & \text { my } \\
\text { intelligence } & \end{array}$ & 3.26 & 0.47 & 1.32 & 0.730 & & & 0.782 & & & & & \\
\hline 12 & $\begin{array}{lr}\text { My } & \text { superior } \\
\text { accentuates } & \text { my } \\
\text { contributions } & \end{array}$ & 3.57 & 0.37 & 1.52 & 0.751 & & & 0.305 & & & & & \\
\hline 13 & $\begin{array}{ll}\text { The opposite } & \text { sex } \\
\text { admires my ideas } & \end{array}$ & 2.83 & 0.31 & 1.36 & 0.792 & & & & 0.614 & & & & \\
\hline 14 & $\begin{array}{l}\text { The opposite sex } \\
\text { ridicules my criticisms }\end{array}$ & 2.79 & 0.51 & 1.75 & 0.749 & & & & 0.725 & & & & \\
\hline 15 & $\begin{array}{l}\text { The opposite sex } \\
\text { debates my mistakes }\end{array}$ & 2.57 & 0.47 & 1.83 & 0.751 & & & & 0.365 & & & & \\
\hline 16 & $\begin{array}{l}\text { The opposite sex } \\
\text { discusses my physical } \\
\text { beauty }\end{array}$ & 2.93 & 0.44 & 1.90 & 0.757 & & & & 0.465 & & & & \\
\hline 17 & $\begin{array}{l}\text { My superior considers } \\
\text { that I am essential }\end{array}$ & 3.05 & 0.36 & 1.47 & 0.758 & & & & & 0.725 & & & \\
\hline 18 & $\begin{array}{l}\text { 1My superior assumes } \\
\text { I must be sexy }\end{array}$ & 3.17 & 0.25 & 1.72 & 0.726 & & & & & 0.321 & & & \\
\hline 19 & $\begin{array}{l}\text { M7i superior considers } \\
\text { that I am capable }\end{array}$ & 3.08 & 0.18 & 1.85 & 0.761 & & & & & 0.425 & & & \\
\hline \multirow[t]{2}{*}{20} & $\begin{array}{l}\text { My superior assumes } \\
\text { that I am smart }\end{array}$ & 3.46 & 0.59 & 1.79 & 0.783 & & & & & 0.537 & & & \\
\hline & $\begin{array}{l}\text { The opposite sex } \\
\text { admires my body }\end{array}$ & 2.70 & 0.92 & 1.37 & 0.749 & & & & & & 0.395 & & \\
\hline 22 & $\begin{array}{ll}\text { The opposite } & \text { sex } \\
\text { compliments } & \text { my } \\
\text { physical beauty } & \end{array}$ & 2.63 & 0.06 & 1.52 & 0.746 & & & & & & 0.461 & & \\
\hline 23 & $\begin{array}{l}\text { The opposite sex } \\
\text { invades my } \\
\text { sentimental privacy }\end{array}$ & 2.81 & 0.21 & 1.73 & 0.716 & & & & & & 0.537 & & \\
\hline
\end{tabular}




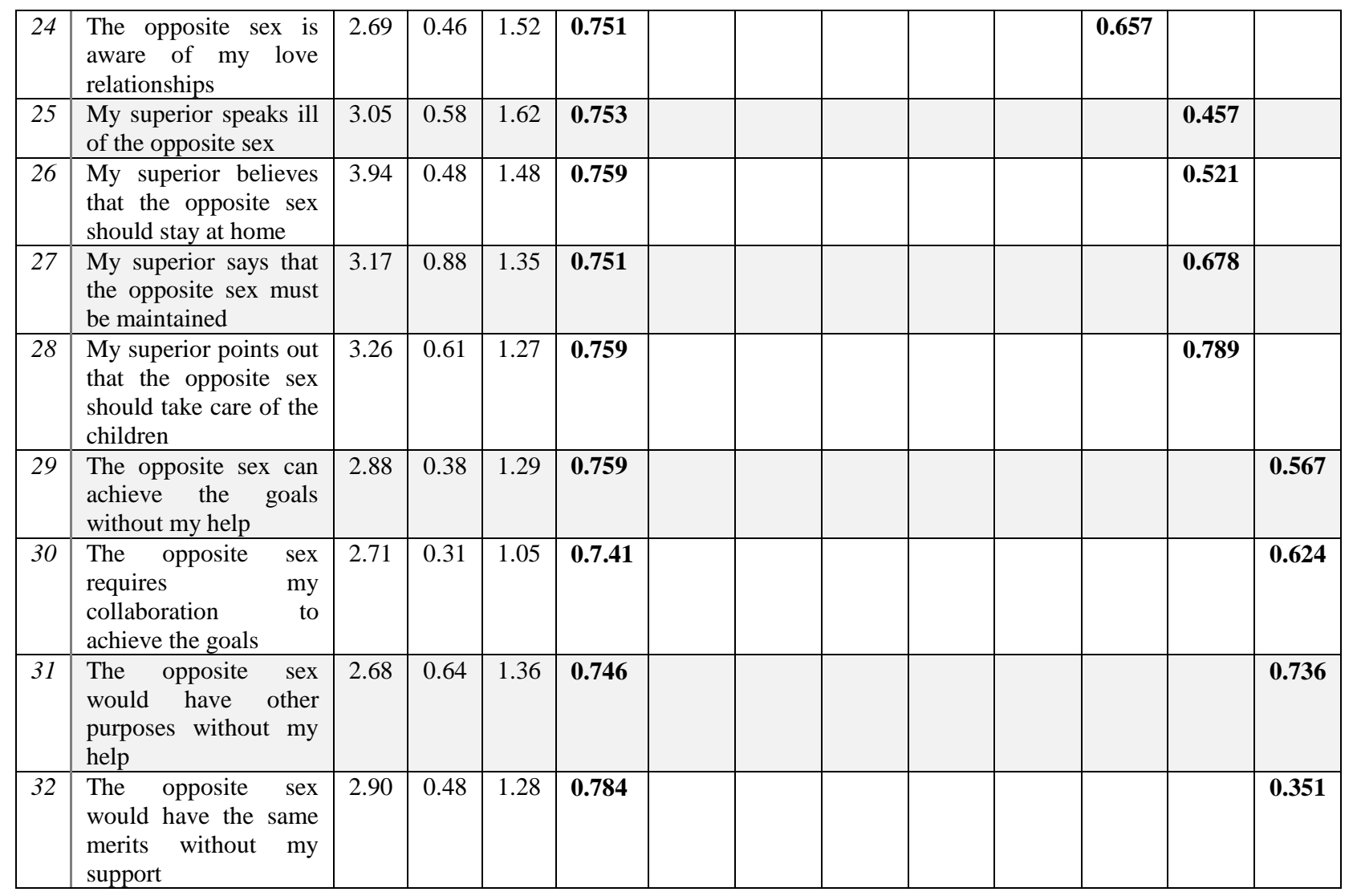

Source: Prepared with the study data: $\mathrm{R}=$ Reactive, $\mathrm{M}=$ Mean, $\mathrm{D}=$ Standard Deviation, $\mathrm{C}=$ Kurtosis, $\mathrm{A}=$ Alpha removing the value of the item. Kurtosis $=2.035$; Bootstrap $=0.000 \mathrm{~F} 1=$ Harassment $(23 \%$ of the variance $), \mathrm{F} 2=$ Benevolence $(22 \%$ of the variance $), \mathrm{F} 3=\mathrm{Reification}(21 \%$ of the variance), F4 = Depersonalization ( $20 \%$ of the variance), F5 = Stigma ( $6 \%$ of the variance), F6 = Harassment $(4 \%$ of the variance $), F 7=$ Prejudice ( $3 \%$ of the variance) , F8 = Subjugation ( $1 \%$ of the variance)

\section{Table 2: Instrument descriptions}

The s correlations greater than 0.300 and less than 0.900 which were established as the threshold required to interpret the construct validity. Even though the principal component analysis with varimax rotation distributed the factorial weights in eight dimensions, the percentages of explained variance indicate that only four meet the minimum essential for testing hypotheses and accepting the fit between the specified relationships and the data obtained.

In this way, the harassment, benevolence, objectification, and depersonalization factors explain $86 \%$ of the total variance.

For harassment was configured with reagents 1 to 4 accounting for $23 \%$ of the variance, kindness included items 5 to 8 and explained $22 \%$ of the variance, objectification was established by the indicators 9 to 12 and obtained $21 \%$ of explained variance. Finally, depersonalization was indicated by symptoms 13 to 16 and obtained $20 \%$ of the variance.

Table 3 shows the correlations between the eight factors in which it is possible to observe their level of significance, but with values of associative relationships close to zero and interpretable as spurious due to their correlation with other unspecified factors.

\begin{tabular}{|c|c|c|c|c|c|c|c|c|c|c|c|c|c|c|c|c|}
\hline & F1 & F2 & F3 & F4 & F5 & F6 & F7 & F8 & F1 & F2 & F3 & F4 & F5 & F6 & F7 & F8 \\
\hline F1 & 1,000 & & & & & & & & 1,871 & 0.549 & 0.540 & 0.659 & 0.671 & 0.540 & 0.543 & 0.540 \\
\hline F2 & $\begin{array}{l}0.292 \\
* *\end{array}$ & 1,000 & & & & & & & & 1,893 & 0.498 & 0.540 & 0.549 & 0.672 & 0.523 & 0.762 \\
\hline F3 & $\begin{array}{l}0.293 \\
* *\end{array}$ & $\begin{array}{l}0.284 \\
*\end{array}$ & 1,000 & & & & & & & & 1,824 & 0.426 & 0.540 & 0.549 & 0.651 & 0.673 \\
\hline F4 & $\begin{array}{l}0.294 \\
* \\
\end{array}$ & $\begin{array}{l}0.629 \\
* * *\end{array}$ & $\begin{array}{l}0.263 \\
* \\
\end{array}$ & 1,000 & & & & & & & & 1,745 & $0.62^{\circ}$ & 0.548 & 0.438 & 0.651 \\
\hline F5 & $\begin{array}{l}0.283 \\
* *\end{array}$ & $\begin{array}{l}0.493 \\
* * *\end{array}$ & $\begin{array}{l}0.123 \\
*\end{array}$ & $\begin{array}{l}0.125 \\
*\end{array}$ & 1,000 & & & & & & & & 1,804 & 0.546 & 0.548 & 0.635 \\
\hline F6 & $\begin{array}{l}0.202 \\
* *\end{array}$ & $\begin{array}{l}0.214 \\
*\end{array}$ & $\begin{array}{l}0.124 \\
*\end{array}$ & $\begin{array}{l}0.546 \\
* * *\end{array}$ & $\begin{array}{l}0.136 \\
*\end{array}$ & 1,000 & & & & & & & & 1,723 & 0.581 & 0.505 \\
\hline
\end{tabular}




\begin{tabular}{|l|l|l|l|l|l|l|l|l|l|l|l|l|l|l|l|}
\hline F7 & $\begin{array}{l}0.181 \\
*\end{array}$ & $\begin{array}{l}0.126 \\
*\end{array}$ & $\begin{array}{l}0.453 \\
* * *\end{array}$ & $\begin{array}{l}0.194 \\
*\end{array}$ & $\begin{array}{l}0.137 \\
* *\end{array}$ & $\begin{array}{l}0.231 \\
*\end{array}$ & 1,000 & & & & & & & & 1,892 \\
\hline F8 & $\begin{array}{l}* .678 \\
* * *\end{array}$ & $\begin{array}{l}0.115 \\
* *\end{array}$ & $\begin{array}{l}0.263 \\
*\end{array}$ & $\begin{array}{l}0.175 \\
*\end{array}$ & $\begin{array}{l}0.147 \\
* *\end{array}$ & $\begin{array}{l}0.236 \\
*\end{array}$ & $\begin{array}{l}0.136 \\
*\end{array}$ & 1,000 & & & & & & \\
\hline
\end{tabular}

Source: Prepared with the study data: $F 1=$ Harassment, $F 2=$ Benevolence, $F 3=$ Objectification, $F 4=$ Depersonalization, F5 = Stigma, F6 = Harassment, $F 7=$ Prejudice, $F 8=$ Subjugation: Level of significance: $*=0.05 ; * *=0.01 ; * * *=0.001$

\section{Table 3: Correlation and covariances between factors}

The first factor on harassment works was significantly associated with the subjugation $(r=0.678 ; p=0.001)$. As the formative violence materializes as harassment, it also intensifies in terms of the confinement of the victim. However, labor benevolence when related to depersonalization and stigma $(r=0.629$ and $r=0.493$ both with $\mathrm{p}=0.001)$ seems to indicate that an increase in comments that attribute to the opposite sex a job function in relation to A position in the family is linked to an increase in the indifference of their merits and the assignment of general attributes to their family, work, or social role.

For its part, the correlation between reification and prejudice $(r=0.453$; $\mathrm{p}=0.001$ ) warn about labor relations in which the sexes are considered instruments around the achievement of objectives that are associated with gender roles.

Finally, depersonalization with harassment $(r=0.546 ; p=0.001)$ seems to demonstrate a process in which the lack of capabilities and $\mathrm{m}$ é labor rites would be associated with the enhancement of physical attributes.

Based on the correlations used, a reflective model of organizational formative violence was specified (see Figure 1). The eight factors validated in which Benevolence is reflective indicator $(\beta=0.69)$. In other words, formative violence in the institution where the study was carried out seems to be indicated by a discourse that discourages equity and consensus.

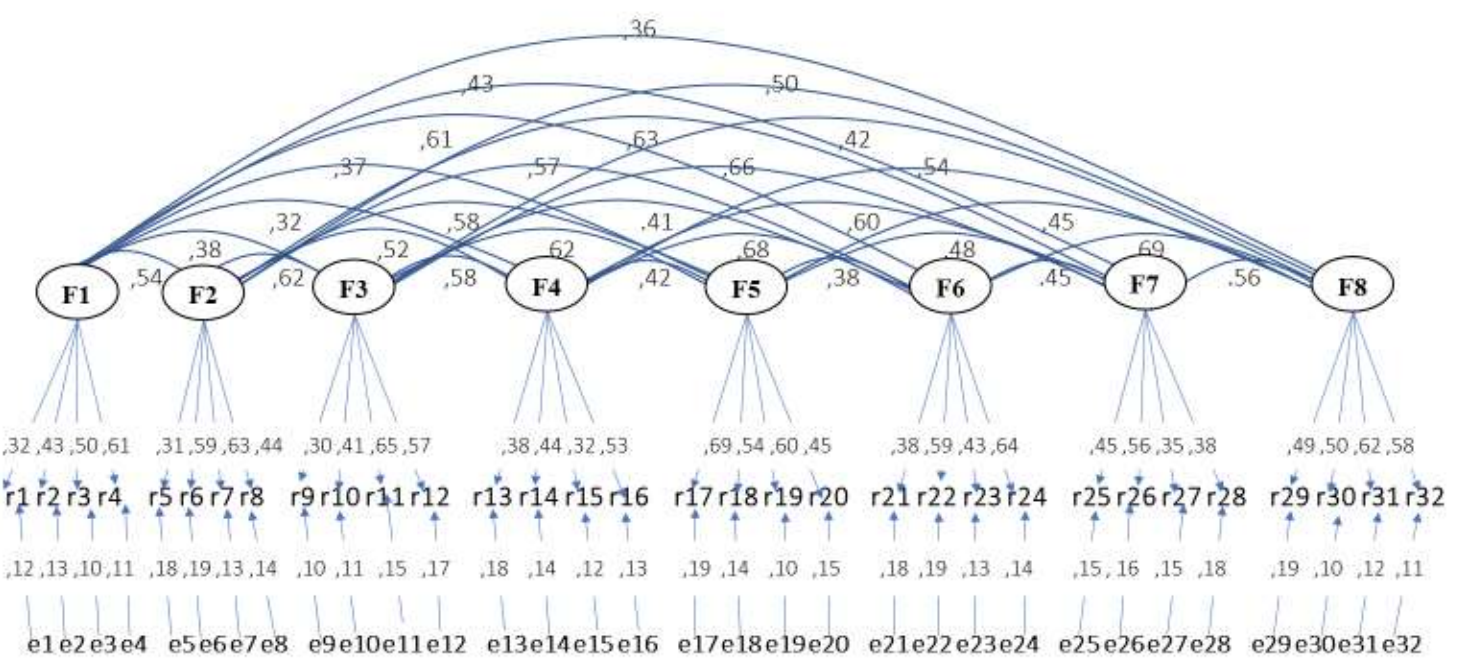

Source: Prepared with the study data: F1 = Harassment, F2 = Benevolence, F3 = Objectification, F4 = Depersonalization, F5 = Stigma, F6 = Harassment, F7 = Prejudice, F8 = Subjugation; e $=$ Error measurement, $\mathrm{R}=$ Reactive, $\leftarrow$ relations between factor and indicator, $\rightarrow$ relation between error and indicator, $\leftrightarrow \rightarrow$ relations between factors

Figure 1. Structural equation modelling

However, the fit parameter and residual $\left[\mathrm{X}^{2}=15.25(2 \mathrm{gl}) \mathrm{p}=0.000\right.$; GFI $=0.950 ; \mathrm{RMR}=0.009$ ] determined the rejection of the null hypothesis. It is true that benevolence is a preponderant symptom of formative violence, but the eight indicators that should make it explicit do not correspond to the answers to the items that measure each of its dimensions.

\section{Discussion}

Compared to studies on workplace violence, which highlight the modeling of negative factors (harassment, mobbing, sabotage) as determinants of positive factors (commitment, innovation, and attention to violence), this study has confirmed eight dimensions where workplace violence is diversified. To be able to build a victim profile in an environment of violence, the state of the art and the present work agree that a work structure of violence prevails, even in innovative organizations with a work commitment.
Johnson and collaborators (2018: p. 623) found that organizational violence was associated with response rate. That is, the discrediting of the employee by your organization prevails over a late response to your case. In the present work, a diversified and systematic organizational violence was found that would correlate with the rate of attention to each of the eight dimensions of violence found in the confirmatory study.

Zalemm and collaborators (2020: p. 11) showed that violence at work negatively and directly determines work commitment (-, 54), although the work environment and organizational culture have a positive impact (, 29 and, 20 respectively). In the present work, it was rather demonstrated that eight factors derived from workplace violence prevail in aspects of work culture and work environment. This is the case of patriarchal benevolence that is distinguished by condescension of the leader towards his employees, as well as the subjugation that supposes the exclusion of people in important positions due to cultural prejudices or traditional norms.

Zhou and collaborators, (2020: p. 10) showed that harassment, sabotage and mobbing directly and negatively affect innovative work behavior (- 
,799; -, 860; -, 648 consecutively). In the present study, it was evidenced as a factor of violence to bullying, which explained the highest percentage of variance in the structure of factors observed (23\%). In other words, harassment is a central factor that explains a phenomenon of workplace violence and negatively determines another structure of innovation at work.

Research lines concerning the modeling and empirical testing of direct, negative, and significant relationships between the factors of organizational violence with the factors of innovation, commitment and attention to labor rights will allow to identify processes of violence that inhibit or increase a culture and an unfavorable or favorable work environment (Fuentes \& Sanchez, 2010; Tajpour, Moradi, \& Jalali, 2018; García, 2020) towards a profile of victims of workplace violence.

Although an approach was made to violence in the family and work context, it is the latter that shows an increment results according to the analysis of the instrument, derived from the perspective conceptual and operational approach with which the items are constituted; however, it should be noted that organizationally reported violence is presented directly from the family nuclei through the roles of social reproduction (Salamzadeh, Nejati, \& Salamzadeh, 2014; Angley, Divney, Magriples, \& Keshaw, 2015; Bae, 2015; García, García, \& Rivera, 2016; Casados, 2020;) as indicated in the literature.

\section{Conclusion}

The present study has established benevolence as the preponderant indicator of formative violence. From this reflective relationship, it can be inferred that in the study sample a discourse is developed regarding the enhancement of self-denial and attention as general attributes of the victims in their professional training process. The contribution of the present study to the state of knowledge is that the organizational climate, being considered as a determining factor of interpersonal relationships and task relationships, could be shaped by a formative violence.

However, it is necessary to explore the dimensions of the organizational climate since workplace violence is only one aspect of the relationships that can be established between employees and managers. It is true that benevolence would explain the absence of hostile sexism in organizations and would anticipate harassment or workplace bullying, but its percentage of explained variance in the work environment would be lower since organizations are focused on responding to work demands rather than to observe equitable and violence-free relationships between their talents. Organizational violence in general and formative violence, indicated by prejudice, depersonalization, benevolence, harassment, subjugation, objectification, stigma, and harassment supposes a process of differentiation between members of an organization that, in the case of Public Institutions of Higher education seems to be inherent to its development since, the training of talents would be gestated at the same time as the training of victims and perpetrators.

One of the contributions of this study is based on the use and management of statistical data such as the validity and confiability indices of the proposed instrument; since they serve as a basis to deepen the behavior and cognitions of the Mexican population specifically but also of Spanishspeaking countries; on the other hand, it also provides empirical evidence to continue building psychometric tools for the diversity of behaviors in organizations.

\section{References}

1. Adenike, A. (2011). Organization climate you as a predictor of employment and job satisfaction. Business Intelligence Journal. 4, 151-166.

2. Angley, M., Divney, A., Magriples, U., \& Kershaw, T. (2015). Social support, family functioning and parenting competence in adolescents parents. Matern \& Child Health Journal, 19 (1), 67-73.
3. Anwar, F. \& Norulkamar, U. (2012). Mediating role of organizational commitment among leaderschip and employee outcomes, and empirical evidence from telecom sector. Processing International Seminar on Industrial Engineering and Management 2, 116-161.

4. Arnau, L. \& Montané, J. (2010). Contributions on the conceptual relationship between attitude and competence, from the theory of change of attitudes. Journal of Research in Educational Psychology. 8, 1283-1302.

5. Bae J. (2015). The impact of social capital on men's mental health from the perspective of social support theory. International Journal of Japanese Sociology, 24 (1), 65-77.

6. Berdecia, Z., González, J., \& Carrasquillo, C. (2012). Leadership Styles for Organizational Success: Multiple Case Studies in Companies. Journal of Advanced Leadership Studies, 1, 21-32.

7. Cardon, M., Gregoire, D., Stevens, C., \& Patel, P. (2013). Measuring entrepreneurial passion: conceptual foundations and scale validation. Journal of Business Venturing, 28, 373-396.

8. Carreón, J. (2014). An exploration of the study of violence. The Mexican case. Obets, 8 (1), 59-78.

9. Carreon, J. (2013). Theories of public safety and perception of crime. Margin, 71, 1-16.

10. Carreón, J., Bustos, J. M., Sánchez, A., Martínez, E., \& García, C. (2020). La estructura del estrés laboral. Investigación Académica Sin Frontera, 13 (32), 1-23.

11. Carreón, J., García, C., Bustos, J. M., Juárez, M., Hernández, J., Sanchez, A., Bernúdez, E., Aldana, W. I., Espinoza, F., Quiróz, C. Y., Bolivar, E., Sandoval, F., R., Coronado, O., Rincón, R. M., Molina, H. D., \& López de Nava, S. (2020). Neural networks of scenarious, phases, roles and discurses of violence of Internet. Journal of Neurology and Neuro Toxicology, 4 (3), 1-9.

12. Carreón, J. (2011). The fight against organized crime in Mexico. Barataria, 14, 59-74.

13. Carreón, J. (2012). Emotions of insecurity determining the distrust of public authority. Electronic Journal of Political Psychology, 31, 52-62.

14. Casados, E. (2020). Violencia doméstica en Veracruz ¿pandemia siliente? UVSERVA, 10, 215-231, consult in: https://doi.org/10.25009/uvserva.v0i10.2721 at 10/12/2020.

15. Castel, G. \& Freundlich, F. (2010). Perceptions of cooperative members and non-members on job satisfaction. Revesco. 103, 33-58.

16. Castro, M. \& Martins, M. (2010). The relationships between organizational climate and employee satisfaction in information and technology organization. Tydskriff vir Bredyfsielkunde. 36, $1-9$.

17. Caykoylu, S., Egri, C., Havlovic, S., \& Bradley, C. (2011). Key organizational commitment antecedents for nurses, paramedical professionals and non-clinical staff. Journal of Health Organization and Management. 25, 7-33.

18. Celik, M., Turunc, O. \& Begenirbas, M. (2011). The role of organizational trust, Burnout and interpersonal deviance for achieving organizational performance. International Journal of Business and Management Studies. 3, 179-190.

19. Cerrón, L. (2010). The role of the market in the construction of vocational training models: the commercialization of the system. Reifop, 13, 54-63.

20. Chaparro, L. (2020). Impacto de la Covid-19 en la violencia contra las mujeres. El caso de Bogota Colombia. Nova, 18 (35), 113-117, consult

in: 
http://www.scielo.org.co/pdf/nova/v18nspe35/1794-2470nova-18-spe35-115.pdf at 30/11/2020.

21. Chiang, M., Méndez, G., \& Sánchez, G. (2010). How job satisfaction influences performance: reatail's company case. Theoria Magazine. 19, 21-36.

22. Chinchilla, N. \& Cruz, H. (2010). Diversity and business paradigms: a new approach. Business and Humanism Magazine, 14, 47-79.

23. Colonel, A. (2010). Training of human capital for a development investment. Eureka, 7, 71-76.

24. Cuesta, A. (2012). Integrated model of human and knowledge management: an application technology. Venezuelan Management Magazine, 57, 86-98.

25. Díaz, C., Hernández, R., \& Roldán, J. (2012). A structural model of the antecedents to entrepreneurial capacity. International Small Business Journal, 30, 850-872.

26. Díaz, S. (2013). The human in the Theory of Organizations. Managerial vision, 12, 45-57.

27. Farzad, F. S., Salamzadeh, Y., Amran, A. B., \& Hafezalkotob, A. (2020). Social Innovation: Towards a Better Life after COVID-19 Crisis: What to Concentrate On. Journal of Entrepreneurship, Business and Economics, 8(1), 89-120.

28. Figeiredo, H., Grau, E., Gil, P., \& García, J. (2012). Work burn syndrome and job satisfaction in nursing professionals. Psocthema, 24, 271-276.

29. Fuentes, A., Herrero, J., \& Gracia, E. (2010). Internet and social support: online sociability and psychosocial adjustment in the information society. Psychological Action. 7, 9-15.

30. Fuentes, F. \& Sánchez, S. (2010). Analysis of the entrepreneurial profile: a gender perspective. Applied Economics Studies, 28, 1-28.

31. Galindo, R. \& Echevarria, M. (2011). Diagnosis of the entrepreneurial culture in the Antioquia engineering school. Journal of the School of Engineering of Antioquia, 15, 85-94.

32. García, C. (2020). Factorial validity structure of occupational stress. Biomedical Journal of Scientific \& Technical Research, 29 (4), 69-72, consult in: http://dx-doi-org/10. BJSTR. MS.ID.004823. at 25/01/2021.

33. García, M., García M., \& Rivera, S. (2016). Significado psicológico del apoyo social. En R. Díaz, S. Rivera, I. Reyes, J. Hernández, y R. García (Eds.) La psicología social en México, XVI, México: AMEPSO, 685-692.

34. Gargallo, A. (2010). Perceptions of cooperative members and non-members on job satisfaction. Revesco, 103, 33-58.

35. Gil, C. (2010). Corporate communicators: challenges of professional training by competencies in the global era. Notebooks, 33, 49-59.

36. Gonzalez, F. Sanchez, S. \& Lopez, T. (2011). Job satisfaction as a critical factor for quality. Studies and Perspectives in Tourism, 20, 1047-1068.

37. Guillén, M. Lleó, A. \& Perles, G. (2011). Rethinking trust as a critical factor in organizational management. Management Notebooks. 11. 33-47.

38. Herrera, B. A., Cárdenas, B. J., Tapia, J. I., \& Calderón, K. N. (2021). Violencia intrafamiliar en tiempos de Covid-19. Polo de Conocimiento, 54 (6), 1027-1038, consult in: https://dx.doi.org/10.23857/pc.v6i2.2334 at 11/01/2021.

39. Holden, R. \& Karsh, B. (2010). Technology Acceptance Model: its past and its future in health care. Journal of Biomedical Informatics. 43, 169-172.

40. Islam, A., Jerin, I., Hafiz, N., Nimfa, D. T., \& Wahab, S. A. (2021). Configuring a blueprint for Malaysian SMEs to survive through the COVID-19 crisis: The reinforcement of Quadruple
Helix Innovation Model. Journal of Entrepreneurship, Business and Economics, 9(1), 32-81.

41. Johnson, A., Nguyen, H., Growth, M., \& White, L. (2018). Workplace aggression and organizational effectiveness: the mediating role of employee engagement. Australian Journal of Management, $43 \quad(4), \quad 614-631$ consult in: https://journals.sagepub.com/doi/pdf/10.1177/0312896218768 378 at 08/12/2020.

42. Kawamorita, H., Salamzadeh, A., Demiryurek, K., \& Ghajarzadeh, M. (2020). Entrepreneurial universities in times of crisis: Case of COVID-19 pandemic. Journal of Entrepreneurship, Business and Economics, 8(1), 77-88.

43. Long, H. (2013). The relationships among learning orientation, market orientation, entrepreneurial orientation, and firm performance. Management Review, 20, 37-46.

44. López, L. \& López, J. (2011). The models of adoption of information technologies from the attitudinal paradigm. Ebape. 9, 176-196.

45. Manning, A. (2010). Development of the psychological climate scale for small business. Journal of New Business Ideas \& Trends. 8, 50-63.

46. Medina, C. (2010). Organizational studies: between unity and fragmentation. Moebio tape, 38, 91-109.

47. Molero, F., Recio, P., \& Cuadrado, I. (2010). Transformational and Transactional Leadership: An Analysis of the Factor Structure of the Multifactor Leardership Questionaire (MLQ). Psicothema. 22, 495-501.

48. Morales, A., Ariza, A., \& Muñiz, N. (2012). The social entrepreneur and e-empowerment of social networks. Journal of Public, Social and Cooperative Economy, 75, 152-177.

49. Omar, A. (2010). Transformative leadership and job satisfaction: the role of trust in the supervisor. Liberabit. 17, 129-137.

50. Orantes, S. (2011). Viability of the Technology Acceptance Model in Mexican companies. An approach to the attitudes and perceptions of users of information technologies. University Digital Magazine. 12, 1-15.

51. Organization Economic Cooperation and Development (2021). Statistic for country. Bruselas: OECD consult in: http://www.oecd.org/ at 03/01/2021.

52. Panamerican Health Organization (2021). Statistic coronavirus SARS Cov-2 and Covid-19 disease in the americas. New York: PAHO consult in: https://www.paho.org/en at 12/01/2021.

53. Prada, R. (2013). Adaptation to change and service: keys to leadership in improving productivity in organizations. Journal of Advanced Leadership Studies, 1, 45-50.

54. Ríos, M., Téllez, M., \& Ferrer, J. (2010). Empowerment as a predictor of organizational commitment in SMEs. Accounting and Administration. 231, 103-125.

55. Rodrígue z, A., Retamal, R., Lizana, J., \& Cornejo, F. (2011). Climate and job satisfaction as predictors of performance: in a Chilean state organization. Health and Society. 2, 219-234.

56. Rojas, R., García, V., \& García, E. (2011). The influence on corporate entrepreneurship of technological variables. Industrial management \& Data System, 111, 9841005.

57. Salamzadeh, A., \& Dana, L. P. (2020). The coronavirus (COVID-19) pandemic: challenges among Iranian startups. Journal of Small Business \& Entrepreneurship, 1-24.

58. Salamzadeh, Y., Nejati, M., \& Salamzadeh, A. (2014). Agility path through work values in knowledge-based organizations: a study of virtual universities. Innovar, 24(53), 177-186. 
59. Shrrof, R., Denenn, C., \& Ng, E. (2011). Analysis of the Technology Acceptance Model in examining student's behavioral intention to use an e-portfolio system. Australasian Journal of Educational Technology. 27, 600-618.

60. Sobrados, L. \& Fernández, E. (2010). Entrepreneurial skills and development of entrepreneurship in educational centers. Education XXI, 13, 15-38.

61. Tajpour, M., Hosseini, E., \& Salamzadeh, A. (2020). The effect of innovation components on organisational performance: case of the governorate of Golestan Province. International Journal of Public Sector Performance Management, 6(6), 817-830.

62. Tajpour, M., Moradi, F., \& Jalali, S. E. (2018). Studying the influence of emotional intelligence on the organizational innovation. International Journal of Human Capital in Urban Management, 3(1), 45-52.

63. Tayo, E. \& Adeyemi, A. (2012). Job involvement \& organizational commitment as determinants of job performance among educational resource center personal. European Journal of Globalization and Development Research. 5, 301-313.

64. Teh, P, Chong, C, Yong, C., \& Yew, S. (2010). Internet self efficacy, computer self - efficacy, and cultural factor on knowledge sharing behavior. African Journal of Business Management. 4, 4086-4095.

65. Tumblers, L. (2010). Entrepreneurship from social representations: the case of Venezuela. Social Sciences, 5, 149165.
66. Vargas, J. (2011). Work organization and job satisfaction: a case study in the footwear industry. Nova Scientia Electronic Magazine. 4, 172-204.

67. Vargas, M. Arenas, M. (2012). Entrepreneurial skills in psychopedagogy students from the Pedagogical and Technological University of Colombia. Journal of Advanced Leadership Studies, 1, 25-30.

68. World Health Organization (2021). Statistic coronavirus SARS Cov-2 and Covid-19 disease in the world. Ginevra: WHO: consult in: https://www.who.int/es at 15/01/2021.

69. Yáñez, R., Arenas, M., \& Ripoll, M. (2010). The impact of interpersonal relationships on job satisfaction. Liberabit. 16, 193-202.

70. Yuangion, Y. (2011). The impact of strong ties on entrepreneurial intention. An empirical study based on the mediating role of self-efficacy. Journal Entrepreneurship, 3, 147-158.

71. Zampetakis, L., \& Moustakis, V. (2013). Entrepreneurial behavior in the Grekk public sector. Emerald, 13, 1-7.

72. Zhou, X., Faiz, S., \& Ma, D. (2020). The relationship between workplace violence and innovative work behavior: mediating roles of employee wellbeing. Healthcare, 8, 332 consult in: http://dx.doi.org/10.3390/healthcare8030332 at 15/12/2020.
This work is licensed under Creative Commons Attribution 4.0 License

To Submit Your Article Click Here:

Submit Manuscript
Ready to submit your research? Choose Auctores and benefit from:

$>$ fast, convenient online submission

$>$ rigorous peer review by experienced research in your field

$>$ rapid publication on acceptance

$>$ authors retain copyrights

$>$ unique DOI for all articles

$>$ immediate, unrestricted online access

At Auctores, research is always in progress.

Learn more https://auctoresonline.org/journals/neuroscience-and-neurologicalsurgery 